\title{
Investigation on Releasing of a Stuck Drill String by Means of a Mechanical Jar
}

\author{
V. Moisyshyn ${ }^{1}$ and K. Levchuk ${ }^{2, *}$ \\ ${ }^{1}$ Department of Higher Mathematics, Ivano-Frankivsk National Technical University of Oil and Gas, Ivano-Frankivsk, 15 Karpatska St., \\ 76019 Ivano-Frankivsk, Ukraine \\ 2 Department of Oil and Gas Equipment, Ivano-Frankivsk National Technical University of Oil and Gas, Ivano-Frankivsk, 15 Karpatska St., \\ 76019 Ivano-Frankivsk, Ukraine \\ e-mail: kgl.imp.nan@gmail.com \\ *Corresponding author
}

\begin{abstract}
Purpose. In this article the most important part is dedicated to the research of elimination of accident that is caused by drill string sticking during the process. That is why it is necessary to develop a mathematical model of the mechanic system: travelling system + drill string + mechanical jar + rock, to develop a computer model for numerical calculation of dynamic characteristics of firing gear. The aim is to use the results of the research and to work out recommendations for expediency of jar application. Methods. For description of the drill string we are using synthesis of the wave theory and theory of the local distortions. For mathematical modeling of firing device we are offering the use of the combined method that combines static solutions of the theory of elasticity for contact zone of drill string and method of a plain wave of Saint-Venant. We solved systems of differential equations using the methods of mathematical physics. An algorithm of the numerical decision which mounted in the computing environment were used at simulation of the longitudinal impact to the stuck drill pipe. In this article we designed a wave chart of the equation system of the drill pipe and conducted step-by-step calculation of a collision momentum. We also designed a computer program for numerical modeling of the drill pipe mechanism with firing gear. We also designed a method of calculation of main dynamic characteristics of firing device that will help analyze and prove the performance of the mechanical jar. A wave diagram was built that shows the impact forces and speeds on the boundary surfaces of the sections of the drill string. There were calculated main dynamic characteristic of mechanical the jar. Originality. Authors also developed a dynamic mathematical model that combined elastic vibrations of continual system of loose part drill pipe, impact mechanisms and discrete movements of a given drill pipe. The process of a mechanical jar work that considers elastic deformations of contact areas was not published by researchers. Practical implications. Received results could be used for further research and perfection of existing engineering methods of modeling and calculations of drill pipes at the stage of their designing and their construction.
\end{abstract}

\section{INTRODUCTION}

The scientific and technical literature broadly covers the methods of elimination Drill String (DS) sticking using firing gear [1]. In general, the mathematical modeling process is quite difficult, therefore to solve specific applied the impact theory we had to use some simplifications and assumptions that satisfy receive convenient engineering solution. Very important also is the right choice of mathematical description of the construction work which is related to the shock [2].

Methods of approximate calculation of impact include:

- classic Newton method, which provides body and solid contact area; 
- Hertz method, which provides solid body and contact areas is elastic;

- elasticity method, which provides elastic body, but the distribution of stress on bodies is immediate;

- plane wave Saint-Venant method;

- combined method that combines lists.

The classical Newton's method gives static elasticity solutions for contact zone and plane wave method to other bodies. Sufficiently accurate results are received if the percussion length of 3-5 times the periods of natural vibrations of the DS. But according to the studies [3] and experimental data [4] blow hammer and anvil last less than $0.1 \mathrm{~s}$, and the greatest period of free oscillations of the drill pipe is $0.2-0.3 \mathrm{~s}$. It should also be noted that the ratio of the classical theory of impact is impossible to determine the duration and force of percussion, tensions in DS, and accelerate their movement.

Despite a sufficient number of publications and developed advanced drilling technologies [5], potential risk of stuck DS is high. Thus, the task of developing new technological solutions and sophisticated technical means to release the drill string sticking remains relevant [6].

Modern methods of elimination stuck are based on the use of mechanical action stuck DS in the area. These methods are based on creating disturbances vibration, percussion or explosive loads applied in the area of the stuck DS. One of the promising areas of DS is releasing drill jars [7], which can eliminate the accident in the most difficult cases.

\section{MATHEMATICAL MODEL OF ELASTIC WAVES EMITTED BY A DRILL PIPE WITH A JAR}

Moving parts of the travelling system are presented by multiple mass $m_{0}=9855 \mathrm{~kg}$ and rigidity of travelling ropes $c_{0}=53 \mathrm{MN} / \mathrm{m}$. Mechanical scheme of DS with a firing gear can be represented by discrete-continuous system comprising four sections (Fig. 1). For research of the selected DS layout we took the parameters that are presented in Table 1. The DS sections are composed of thin cylindrical steel pipes with outside diameter $D$, inside diameter $\mathrm{d}$ and total length $l$. Stuck part of the drill string will be divided into two sections: the third - a loose part, located above sticking zone and the fourth - stuck DS part. The density of the drilling fluid is $q=1200 \mathrm{~kg} / \mathrm{m}^{3}$. Young's modulus (modulus of elasticity) for all three sections is $E=210 \mathrm{GPa}$. Coefficient of dry friction was taken $f_{0}=0.3$ to the fourth section.

The mathematical model for the proposed scheme: travelling block + loose drill string + mechanical jar + sticking drill string (Fig. 1) describes dynamic processes in DS. According to the theory of elasticity [8], wave

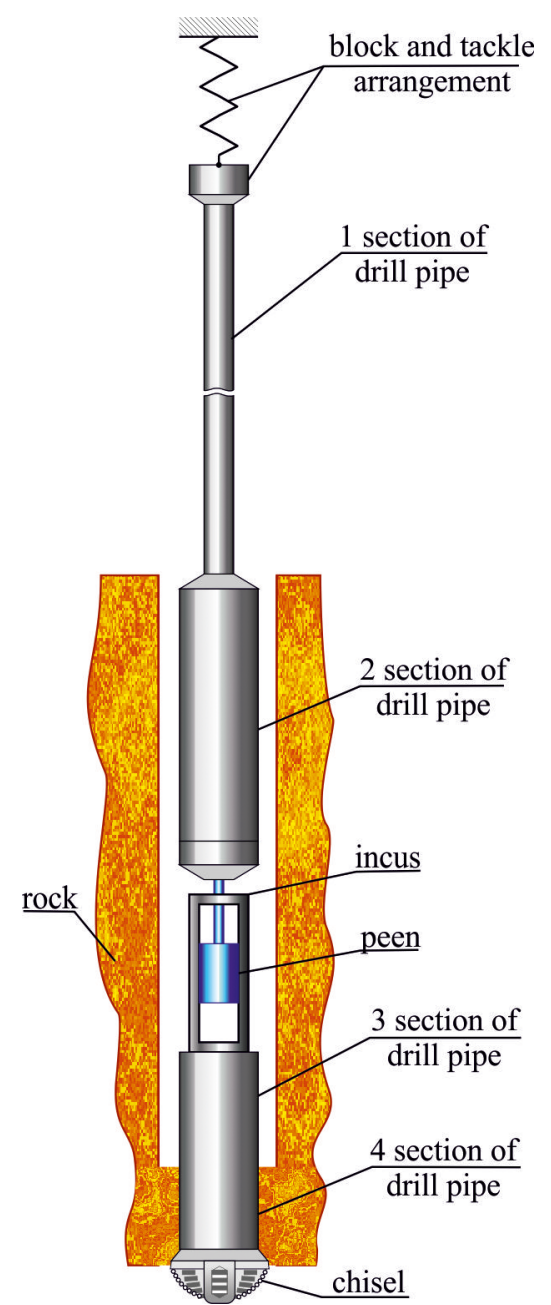

Figure 1

Drill string with built-in mechanical jar.

differential equations [9] for the cross-cuts of each of the four sections can be written as:

$\ddot{u}(x, t)+2 h \dot{u}(x, t)-a^{2} u^{\prime \prime}(x, t)=g-f_{0} \operatorname{sign}[\dot{u}(x, t)]$,

where $\ddot{u}(x, t)=\frac{\partial^{2} u(x, t)}{\partial t^{2}} ; h=\frac{\alpha}{2 m}-$ multiple coefficient of viscous resistance ( $\alpha$ - coefficient drilling fluid interaction with DS section, $m=\rho F l$ - mass of section); $F$ - cross sectional area of drill pipes; $a=\sqrt{\frac{E}{\rho}}-$ speed of elastic waves propagation ( $E-$ Young's modulus); $u^{\prime \prime}(x, t)=\frac{\partial^{2} u(x, t)}{\partial x^{2}} ; g$ - gravitation acceleration; $f_{0}$ - coefficient of DS dry rod friction; $x$ - current coordinate of DS section cross-cut; $t$ - current time. 
TABLE 1

Geometric parameters of the DS layout.

\begin{tabular}{c|c|c|c|c|c}
\hline Section number & $\rho\left(\mathrm{kg} / \mathrm{m}^{3}\right)$ & $D(\mathrm{~mm})$ & $d(\mathrm{~mm})$ & $l(\mathrm{~m})$ & $\alpha(\mathrm{kg} / \mathrm{s})$ \\
\hline 1 & 7869 & 127.0 & 107.0 & 71.4 & 1400 \\
\hline 2 & 7759 & 177.8 & 71.4 & 130 & $l_{3}$ \\
\hline 3 & 7759 & 177.8 & $d_{4}$ & 48.4 & 380.4 \\
\hline 4 & $\rho_{4}$ & $D_{4}$ & $l_{3}$ & 380.4 \\
\hline
\end{tabular}

Next, we have to attach boundary conditions at the ends and docking sections of DS to the dynamic equations of the drill string motion:

$$
\begin{array}{r}
E_{1} F_{1} u_{1}^{\prime}(0, t)+m_{0} g=c_{0} u_{1}(0, t)+m_{0} a_{1}^{2} u_{1}^{\prime \prime}(0, t) ; \\
u_{1}\left(l_{1}, t\right)=u_{2}(0, t) ; \\
E_{1} F_{1} u_{1}^{\prime}\left(l_{1}, t\right)=E_{2} F_{2} u_{2}^{\prime}(0, t)+q\left(F_{2}-F_{1}\right) g l_{1} ; \\
E_{2} F_{2} u_{2}^{\prime}\left(l_{2}, t\right)=-q F_{2} g\left(l_{1}+l_{2}\right) ; \\
E_{3} F_{3} u_{3}^{\prime}(0, t)=-q F_{3} g\left(l_{1}+l_{2}\right) ; \\
u_{3}\left(l_{3}, t\right)=u_{4}(0, t) ; \\
E_{3} F_{3} u_{3}^{\prime}\left(l_{3}, t\right)=E_{4} F_{4} u_{4}^{\prime}(0, t)+ \\
q\left(F_{4}-F_{3}\right) g\left(l_{1}+l_{2}+l_{3}\right) .
\end{array}
$$

From static equilibrium equations of the mechanical system we got initial motion conditions $u_{i}\left(x_{i}, 0\right)$ :

$$
\begin{gathered}
-E_{1} F_{1} u_{1}^{\prime}\left(x_{1}, 0\right)+\rho_{1} F_{1}\left(l_{1}-x_{1}\right) g+\rho_{2} F_{2} l_{2} g \\
+q\left(F_{2}-F_{1}\right) l_{1} g-q F_{2}\left(l_{1}+l_{2}\right) g+F_{p}=0 ; \\
-E_{2} F_{2} u_{2}^{\prime}\left(x_{2}, 0\right)+\rho_{2} F_{2}\left(l_{2}-x_{2}\right) g \\
-q F_{2}\left(l_{1}+l_{2}\right) g+F_{p}=0 ; \\
E_{3} F_{3} u_{3}^{\prime}\left(x_{3}, 0\right)=\rho_{3} F_{3} x_{3} g+q F_{3}\left(l_{1}+l_{2}\right) g-F_{p}=0 ; \\
-E_{4} F_{4} u_{4}^{\prime}\left(x_{4}, 0\right)+\rho_{4} F_{4}\left(l_{4}-x_{4}\right) \\
-q F_{4}\left(l_{1}+l_{2}+l_{3}+l_{4}\right) g-P_{s t}=0 ;
\end{gathered}
$$

where $P_{s t}-$ stuck force of the drill string. Indexes in equations (2)-(9) indicate the number of section.

At the beginning of the motion in the position of static equilibrium speeds in the current DS cross-cuts are $\dot{u}_{i}\left(x_{i}, 0\right)=0$.

\section{METHODS DETERMINING THE BOUNDARIES OF THE STICKING DRILL STRING}

Before a decision on the choice of the liquidation of the accident, we should determine the type and location of stuck. The simplest way to determine the upper boundary sticking is an approximate calculation [10]. At the same time, it is believed that every $1000 \mathrm{~m}$ loose part of the stuck DS with force an effort that exceeds its own weight the drill string $200 \mathrm{kN}$ is stretched in accordance with Table 2.

The upper boundary of stuck places is usually determined by the formula:

$$
l_{s t}=l_{1}+l_{2}+E_{3} F_{3}\left(\frac{1.05 \Delta l}{P_{1}-P_{2}}-\frac{l_{1}}{E_{1} F_{1}}-\frac{l_{2}}{E_{2} F_{2}}\right)
$$

where 1.05 - coefficient takes into account hard locks; $P_{1}$, $P_{2}$ - tensile forces; $\Delta l$-elongation the drill string with the subtraction load $P_{1}-P_{2}$. For the selected layout of the drill string:

$$
l_{s t}=\frac{4.59 \Delta l}{P_{1}-P_{2}} \cdot 10^{9}-5143.8, m
$$

An oilman determines a place of the sticking DS more precisely using the identification stuck. This device is the electromagnet, the effect of which is based on the conversion of the sensor indications of magnetic waves in a stick impulses induction of electromotive force [11]. These indications are transmitted by cable to the drilling rig and recorded. Slight areas of pipes are magnetized using the direct current.

Acoustic cement bond log sonde is the most advanced method to determine the place of the sticking and allocation of plots with different degrees of pressing [12]. Amplitude and duration distribution refracted waves are measured using acoustic logging. Emitter generates sound pulses at a frequency of 10-30 Hz, which picks up the receiver. Elastic vibrations transmitted through the drilling fluid in DS, in which waves propagate at the speed of sound. Locations are stuck by a loss of energy that is not returned to the receiver. The intensity of the forces are measured at magnitude stuck 
TABLE 2

Lengthening drill pipes.

\begin{tabular}{l|l|l|l|l}
\hline Pipe diameter, mm & 114 & 127 & 140 & 168 \\
\hline Lengthening, cm & 35 & 30 & 25 & 20 \\
\hline
\end{tabular}

energy that is absorbed by the rock. As a result of geophysical studies wells can get the curve that allows you to allocate areas of the sticking DS intensity and pressure forces distributed rocks in the pipe.

\section{THE STICKING DRILL STRING}

The drill pipe and the rock hole that surrounds it should be considered as a single structure in the case of simulation of wave characteristics of fourth section of the sticking DS. Given the density $\rho_{r}=3000 \mathrm{~kg} / \mathrm{m}^{3}$ and Young's modulus $E_{r}=129 \mathrm{GPa}$ of rock we calculated multiple density $\rho_{4}$, multiple cross sectional area $F_{4}$ and multiple Young's modulus $E_{4}$. Thus, the sticking drill pipe consists of two bodies: steel pipe and rock stuck, unlimited nested in the hills. If we consider the section of described construction, the conditional parameters of rock stuck are completely determined by the stuck power pressure rock $P_{s t}$, which is the sticking drill pipe (Fig. 2):

$$
\begin{gathered}
P_{s t}=\int_{0}^{l_{4}} \int_{\varphi_{1}}^{\varphi_{2}} f\left(x_{4}, \varphi\right) d \varphi d x_{4} \\
F_{r}=\frac{P_{s t}}{\rho_{r} l_{4} g} ; \quad F_{4}=F_{3}+\frac{P_{s t}}{\rho_{r} l_{4} g} ; \\
\rho_{4}=\frac{\rho_{3} F_{3}+\rho_{r} F_{r}}{F_{3}+F_{r}} ; \quad E_{4}=\frac{E_{3} F_{3}}{F_{3}+F_{r}},
\end{gathered}
$$

where $f\left(x_{4}, \varphi\right)$ - distributed power intensity rock stuck; $\rho_{r}$, $F_{r}$ - rock density and rock strength equivalent cross-cut of the rock sticking area.

\section{WAVE MODEL OF A MECHANICAL JAR}

Let us review a percussion of two parts of the drill string. We consider the impact as being elastic: the possibility of residual deformation and dissipation energy is excluded. Therefore, during the formation of waves of an absolutely elastic percussion, we can observe the division of the energy into kinetic and potential. The process of partial transformation of kinetic energy into potential energy gradually spreads on adjacent layers of the drill pipe, whereas
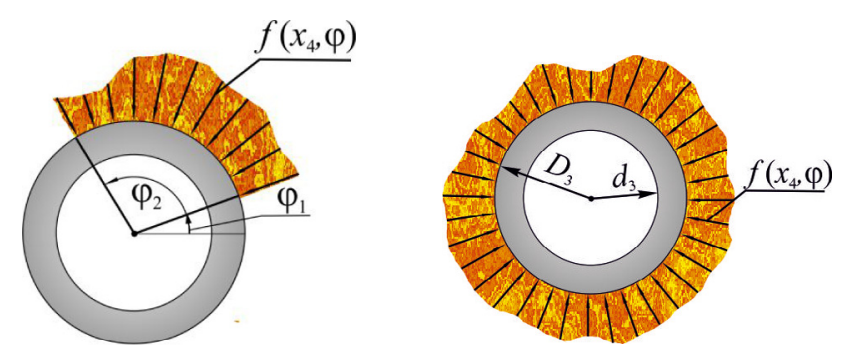

Figure 2

Cross-cut sticking drill pipe.

deformation spreads from one section to another section. When a percussion wave moves on rod of the drill string, starting from impact zone, dynamic characteristics change is explained by material properties and cross-cuts of the drill pipes, as well as explained by the external environment. According to this, we will consider that the parameters of the wave, moving on rod of the drill string, will not change till it reaches the boundary surface. The boundary surfaces in DS are the following: end sections, adjusted to each other, and stuck surface of the drill string.

The demonstrated mechanic system (Fig. 1) has four boundary surfaces. As a result, a multiple reflection, refraction and imposition of shock waves are possible. It can cause a complication of general picture of wave process. This is why it is advisable to draw a wave diagram (Fig. 3), so as to demonstrate the drill pipes' wave process. From Figure 3, we can see $t=\frac{l}{a}$ - the duration of the impact motion wave between the sections of the drill string; $\vec{N}_{0}$ and $\vec{n}_{0}$, $\vec{S}_{0}$ and $\vec{s}_{0}, \vec{R}_{0}$ and $\vec{v}_{0}, \vec{Q}_{0}-$ efforts and speed on the section borders of the drill string before the percussion; $\vec{S}, \vec{R}, \vec{Q}$ - impact forces; $\vec{s}, \vec{v}, \vec{w}-$ the speed of the waves between sections of the drill string.

Since all pipes are forged from the same material, and the distance between the impact zones and the drill string sticking $l_{3}<l_{2}<l_{1}$, thereafter $t_{3}<t_{2}<t_{1}$. Thus, the bouncing from the top of the drill string will take place $n_{1}=\left[\frac{t_{1}}{t_{2}}\right]$ times less than from the first section of the drill string and, consequently, $n_{2}=\left[\frac{t_{2}}{t_{3}}\right]$ times less than from the stuck boundary surface of the drill pipe. The percussion will be lasting as long as the impact forces will be gaining positive values and both components of the drill string will spring back.

The wave diagram is an important element in order to graph wave equation. At the beginning of a percussion, burdened drill pipes with end speed $\vec{v}_{0}$ and ultimate tensile strength $\vec{R}_{0}$ met with anvil - sticking component of the drill string, while its upper butt had a speed $\vec{k}_{0}$ and a strike force $\vec{K}_{0}$ :

$$
\left\{\begin{array}{l}
R_{1}-R_{0}=A_{2} F_{2}\left(v_{0}-v_{1}\right) \\
R_{1}-K_{0}=A_{3} F_{3}\left(k_{0}-v_{1}\right)
\end{array}\right.
$$




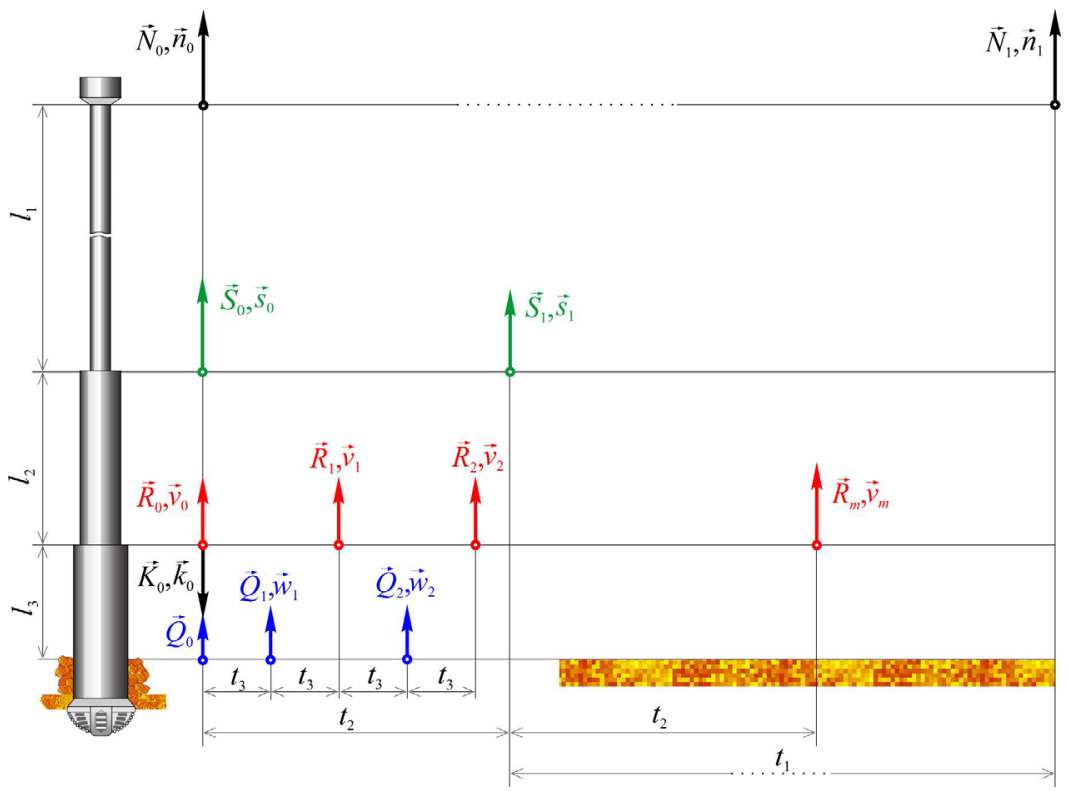

Figure 3

Wave diagram of the drill string.
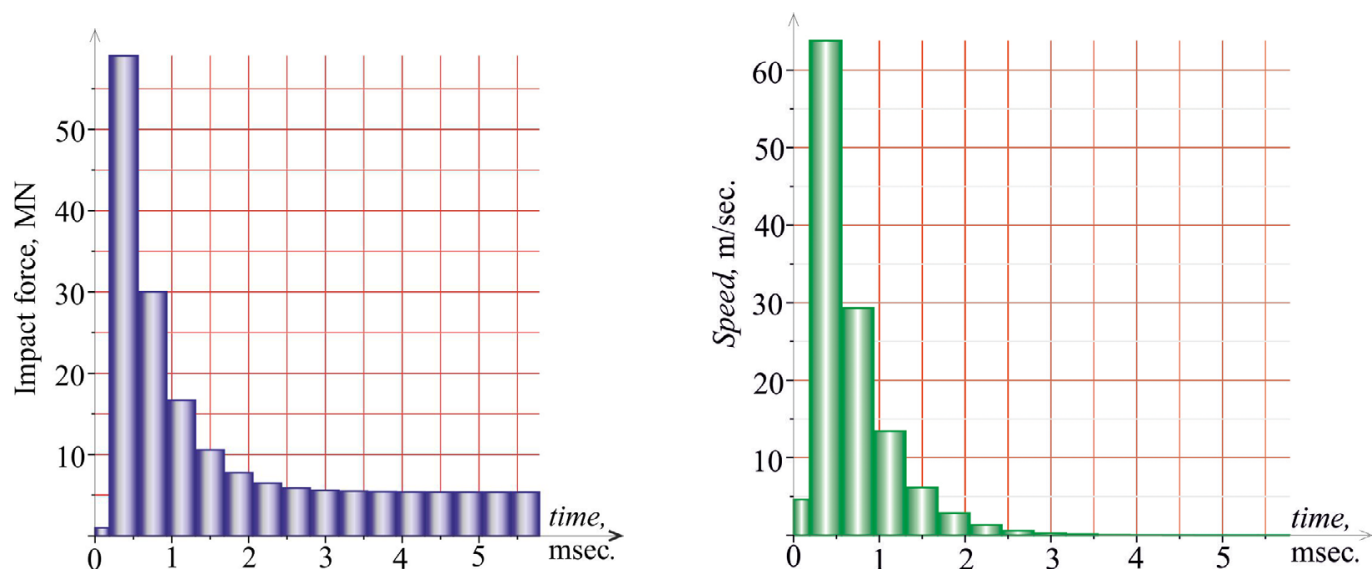

Figure 4

Laws changing impact strength and speed of the stuck area of the drill string and for the pressure rocks $P_{s t}=120 \mathrm{kN}$.

From the emplacement, percussion wave with force $\vec{K}_{0}$ and speed $\vec{k}_{0}$ spreads on the third section of the DS and then lapse of $t_{3}$ reaches the stuck place of a static forth section of the drill string, under the force of $\vec{Q}_{0}$ :

$$
\left\{\begin{array}{l}
Q_{1}-K_{0}=A_{3} F_{3}\left(k_{0}-w_{1}\right) \\
Q_{1}-Q_{0}=-A_{4} F_{4} w_{1}
\end{array}\right.
$$

Similarly, in the following intervals $2 t_{3}$, impact forces on the drill pipes' boundary sections DS (Fig. 3) can be calculated from the following equation system:

$$
\begin{aligned}
& \left\{\begin{array}{l}
R_{i}-R_{i-1}=A_{2} F_{2}\left(v_{i-1}-v_{i}\right) ; \\
R_{i}-Q_{i}=A_{3} F_{3}\left(w_{i}-v_{i}\right),
\end{array}\right. \\
& \left\{\begin{array}{l}
Q_{i}-R_{i-1}=A_{3} F_{3}\left(v_{i-1}-w_{i}\right) ; \\
Q_{i}-Q_{i-1}=A_{4} F_{4}\left(w_{i-1}-v_{i}\right),
\end{array}\right.
\end{aligned}
$$

where $i=2, \ldots, 2 n_{2}$. The lower part of the first section of the drill string, which had, before the percussion, speed $\vec{s}_{0}$ and tensile strength $\vec{S}_{0}$ will meet through the time interval $t_{2}$ 

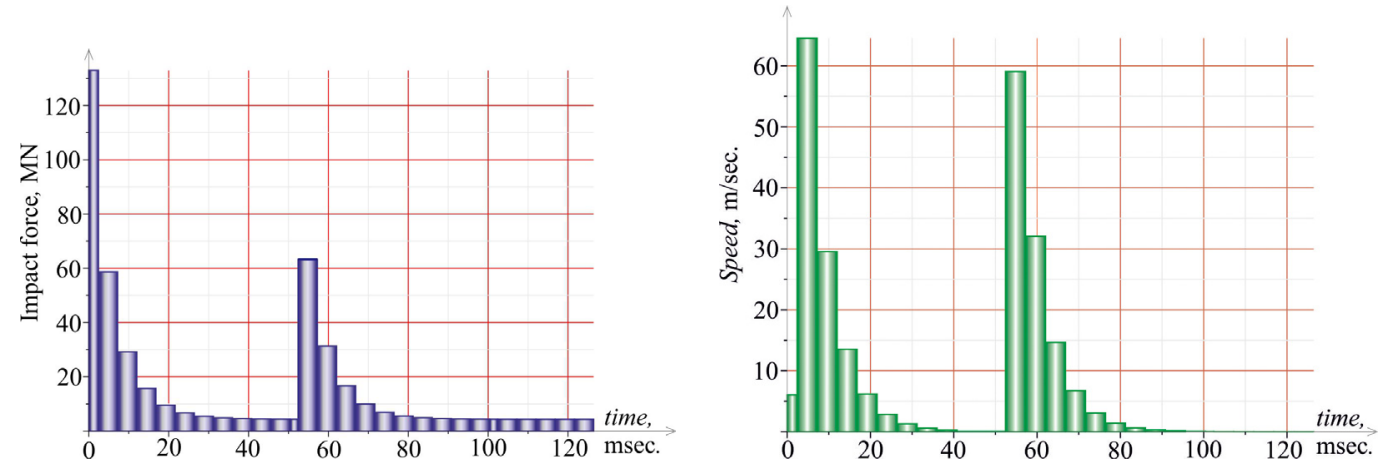

Figure 5

Laws changing impact strength and speed of the stuck area of the drill string and for the pressure rocks $P_{s t}=90 \mathrm{kN}$
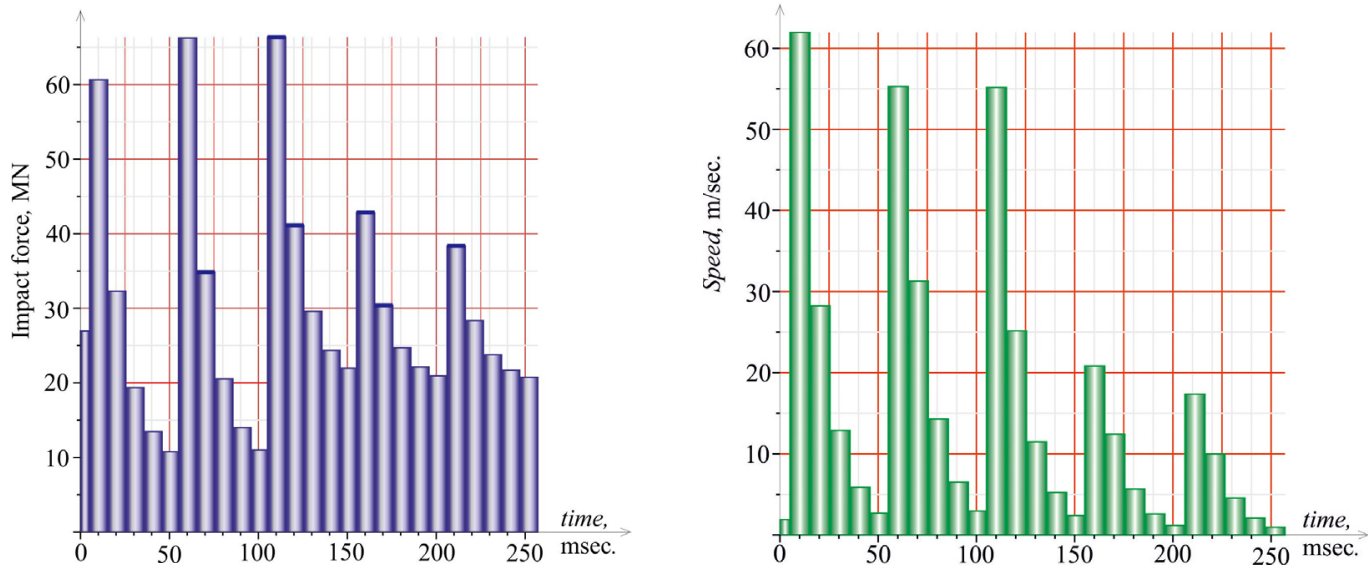

Figure 6

Laws changing impact strength and speed of the stuck area of the drill string and for the pressure rocks $P_{s t}=50 \mathrm{kN}$.

with the wave, which had spread with speed $\vec{v}_{0}$ and force $\vec{R}_{1}$ :

$$
\begin{gathered}
\left\{\begin{array}{l}
S_{1}-S_{0}=A_{1} F_{1}\left(s_{0}-s_{1}\right) ; \\
S_{1}-R_{0}=A_{2} F_{2}\left(v_{0}-s_{1}\right),
\end{array}\right. \\
\left\{\begin{array}{l}
R_{2 n_{2}+1}-S_{1}=A_{2} F_{2}\left(s_{1}-v_{2 n_{2}+1}\right) ; \\
R_{2 n_{2}+1}-R_{2 n_{2}}=A_{3} F_{3}\left(v_{2 n_{2}}-v_{2 n_{2}+1}\right) .
\end{array}\right.
\end{gathered}
$$

Here $A_{i}=\sqrt{\rho_{i} E_{i}}, i=1-4-$ the impedance of the type of barrel drill hole. Impact forces and speeds are calculated stepby-step from these equation systems (14)-(17). Similarly for the upper part of the drilling string, which had, before the strike, speed $\vec{n}_{0}$ and tensile strength $\vec{N}_{0}$ will meet with a wave after a certain time $t_{1}$, that derived from the second section with the speed $\vec{s}_{1}$ and force $\vec{S}_{1}$. Speeds $\vec{n}_{1}, \vec{s}_{1}$ and forces $\vec{N}_{1}, \vec{S}_{1}$ are calculated from the following equation systems:

$$
\left\{\begin{array}{l}
N_{1}-N_{0}=A_{\text {air }} F_{1}\left(n_{0}-n_{1}\right) ; \\
N_{1}-S_{1}=-A_{1} F_{1}\left(s_{1}-n_{1}\right) .
\end{array}\right.
$$

where $A_{\text {air }}=\sqrt{\rho_{\text {air }} E_{\text {air }}}-$ air impedance. It is important to mention that impact force appears later in the sticking zone than in the zone of an actual percussion. This delay depends on the general distance between anvil, the place of the sticking of the DS and the type of borehole, so it means that it can be calculated due to duration of the wave's passage till the place sticking $t_{3}$. The strike will be lasting till the moment when the force $\vec{R}_{i}$ becomes negative and both parts of the drilling stick will spring back. Usually the wave never reaches the top of the drill stick, as till that moment $t_{1}+t_{2}$ percussion ends up.

\section{FINDINGS}

The research was conducted for the chosen component of the drill string with the modeling of different length sticking force with equally distributed load. The given wave dependencies are demonstrated in Figure 4.

The duration of the percussion was defined by the period of time from the moment of meeting $t_{u}$ till the moment of separation of the hammer and the anvil. According to the wave diagram (Fig. 3) release of the sticking zone was considered as step-by-step summary displacement.

In case the integral impact forces occur by $P_{s t}$ and they exceed $100 \mathrm{kN}$, wave diagrams will have impulsive shape. And the collision momentum itself responds to the Hertz 
TABLE 3

Dynamic characteristics of the mechanical jar.

\begin{tabular}{c|c|c|c}
\hline Rock pressure forces & Strike duration & Energy & Number of strikes \\
\hline$P_{s t}(\mathrm{kN})$ & $\tau(\mathrm{ms})$ & $E(\mathrm{MJ})$ & Nud \\
\hline 120 & 6 & 0.67 & 887 \\
\hline 114 & 21 & 0.22 & 247 \\
\hline 108 & 36 & 0.50 & 140 \\
\hline 102 & 52 & 0.69 & 92 \\
\hline 95 & 64 & 0.75 & 64 \\
\hline 88 & 124 & 1.56 & 24 \\
\hline 82 & 143 & 1.97 & 20 \\
\hline 75 & 203 & 3.66 & 13 \\
\hline 68 & 254 & 6.73 & 8 \\
\hline 38 & 256 & 8.45 & 4 \\
\hline
\end{tabular}

theory: at early convergence of hammer and anvil it quickly increases to the maximum value than it decreases till the complete stop of the drill string. The maximum value of impact force can reach tens of MN. Such stuck is characterized by length of the sticking zones more than $30 \mathrm{~m}$ or in places of strong monolithic formations. It is important to add that in practice the drillers meet with several sticking areas, and the sticking length does not exceed more than $20 \mathrm{~m}$ (Figs. 5 and 6).

From the researches we can see that with a decrease of pressure force of the rock on the drill pipe, the number of peaks of impact forces on wave diagrams and the speed of liberation of the drill string increase, and collision momentum takes the form of smooth curves.

Since every cross-cut of the drill string's sticking gets negative speed, explained by elastic deformation, and some of the sections - characteristics of the material, therefore the kinetic energy of the drill string before percussion will have integral form:

$$
T=\frac{1}{2} \sum_{j=1}^{3} \int_{0}^{l_{j}} \dot{u}_{j}^{2}\left(x_{j}, t_{u}\right) \rho_{j} F_{j} d x_{j}
$$

where $\dot{u}\left(x, t_{u}\right)$ is the speed of cross-cut of the section DS with coordinate $x$ at the meeting moment of hammer and anvil $t_{u}$. The common energy that sticking area gets after the percussion can be calculated as such:

$$
A=t_{3}\left(R_{0} v_{0}+2 \sum_{j=1}^{N u d} R_{j} v_{j}\right)+2\left(t_{2}-n_{2} t_{3}\right) \sum_{j=1}^{\frac{N u d}{n_{2}}-1} R_{j n_{2}} v_{j n_{2}} .
$$

With the help of elaborated computer program for a chosen composition of the drill string, we calculated time of meeting of hammer and anvil $t_{u}=28 \mathrm{~ms}$, if the way of shock mechanism $s=3 \mathrm{~m}$, rock pressure forces $P_{s t}$, percussion duration $\tau$, energy $A$, that was transmitted to the drill string sticking and the number of percussion $N u d$, needed to liberate the drill string. The results of calculations are summarized within Table 3.

\section{CONCLUSION}

In this study we obtained mathematical and computer model of the firing gear, triggered with the help of longitudinal vibrations of the drill string. Those vibrations were generated by multiple harmonics spectrum. The given theory of dynamic modeling of the drill pipe with a mechanical jar gives us an opportunity to calculate the process of accident liquidation. One should take into account that mechanical jar is embedded into drill pipes section.

The researches have shown [1] that the rapidity of stuck liquidation depends on rock elasticity. The fastest method allows us to release the drill string from loam $\left(E_{r}=33 \mathrm{GPa}\right)$, and the longest from crushed stone $\left(E_{r}=50 \mathrm{GPa}\right)$ and sandy loam $\left(E_{r}=78 \mathrm{GPa}\right)$.

The graphics show that after the meeting with a rock, the collision momentum of plane wave of the drill string (with an increase of rock pressure forces on the pipe) has lower duration and impulsive character. Therefore, while calculating we should take into account geographical data, which will enable us to define the number of stuck, its areas and length, as well as distributed force power on the pipe.

\section{ACKNOWLEDGMENTS}

We express our sincere gratitude to Dr. Ja. Kuntsyak (Joint Stock Company «Scientific Design Bureau for Testing of Drilling Tools », Kyiv, Ukraine) and Prof. V. Vekeryk (Ivano-Frankivsk National Technical University of Oil and Gas, Ukraine) for consultations on technical issues of borehole drilling.

Scientific advice was obtained from The National Academy of Sciences of Ukraine, Academic Society of Michal Baludyansky (Bratislava, Slovak Republic).

We greatly appreciate Prof. O. Ivasyshyn (G.V. Kurdyumov Institute for Metal Physics of the National Academy Sciences of Ukraine) for his valuable improvements in this manuscript.

\section{REFERENCES}

1 Dupriest F.E., Elks W.C., Ottesen S. (2011) Design methodology and operational practices eliminate differential sticking, SPE Drill. Complet. 26, 115-123. 
2 Hempkins W.B., Kingsborough R.H., Lohec W.E., Nini C.J. (1987) Multivariate statistical analysis of stuck drill pipe situations, SPE Drill. Eng. 2, 237-244.

3 Levchuk K. (2015) Influence of location of the shock absorber on the performance of a shock pulse alarm layout of the drill string (Ukraine), Inf. Syst. Mech. Control 12, 72-83.

4 Skeem M.R., Friedman M.B., Walker B.H. (1979) Drill string dynamics during jar operation, SPE J. Petrol. Technol. 31, 1381-1386.

5 Shook E.H., Lewis T.W. (2008) Cement bond evaluation, in: SPE Western Regional and Pacific Section AAPG Joint Meeting, 29th March to 4th April 2008, Bakersfield, California, USA.

6 Shivers R.M., Domangue R.J. (1993) Operational decision making for stuck pipe incidents in the Gulf of Mexico: a risk economics approach, SPE Drill. Complet. 8, 125-130.

7 Kyllingstad A., Halsey G.W. (1990) Performance testing of jars, in: SPE/IADC Drilling Conference, 27th February to 2nd March, 1990, Houston, TX.

8 Shatskii I.P., Perepichka V.V. (2013) Shock wave propagation in an elastic rod with a viscoelastic external resistance, J. Appl. Mech. Tech. Phys. 8, 1016-1020.
9 Evans L. (1998) Partial differential equations, American Mathematical Society, Providence, p. 662.

10 Borwein J.M., Skerritt M.P. (2012) An introduction to modern mathematical computing with Maple, Springer Undergraduate Texts in Mathematics and Technology, p. 233.

11 McCall K.R., Boudjema M., Santos I.B., Guyer R.A., Boitnott G.N. (2001) Nonlinear, hysteretic rock elasticity: deriving modulus surfaces, in: American Rock Mechanics Association DC Rocks, The 38th U.S. Symposium on Rock Mechanics (USRMS), 7-10 July, 2001, Washington.

12 Siems G.L., Boudreaux S.P. (2007) Applying radial acoustic amplitude signals to predict intervals of sand-stuck tubing, SPE Prod. Oper. (Society of Petroleum Engineers) 22, 254-259.

Manuscript submitted in 9 October 2016 Manuscript accepted in 10 July 2017 Published online in September 2017 